NOTAS 



\title{
LA FUNCIÓN DE LOS PARTIDOS Y EL PARLAMENTO
}

\author{
MARTIN MORLOK ${ }^{1}$ \\ Catedrático de Derecho Público de la Universidad de Düsseldorf \\ Director emérito del Instituto de Partidos de la Universidad de Düsseldorf
}

\section{SUMARIO}

I. La función de los partidos políticos. II. Los grupos parlamentarios como brazo parlamentario de los partidos

\section{LA FUNCIÓN DE LOS PARTIDOS POLÍTICOS}

\section{La democracia como condicionamiento institucional del poder}

La democracia implica condicionamiento. Una democracia constitucional diseña instituciones para que el pueblo pueda condicionar tanto la adopción de decisiones como su ejecución. La Constitución y las leyes diseñan los canales institucionalizados de condicionamiento, a través de los cuales los ciudadanos pueden influir en la toma de decisiones políticas. La expresión „condicionamiento ha sido aquí consciente y cuidadosamente elegida, ya que el ideal normativo de „determinación« de la política por parte de los ciudadanos minusvalora los márgenes de actuación que permanecen en el sistema político a pesar de las directrices democráticas. La expresión aquí empleada toma también en consideración cuestiones fácticas. Entre las estructuras institucionalizadas del input se encuentra, en primer lugar, el Parlamento, que debe adoptar las decisiones políticas fundamentales. Es el órgano central de la democracia.

El procedimiento central del condicionamiento democrático son las elecciones parlamentarias.

1 Traducción de Leonardo Alvarez Alvarez, Profesor Titular de Derecho Constitucional de la Universidad de Oviedo. Este trabajo se publica en el marco del Proyecto DER 2017-84733-R: Partidos políticos, origen, función y revisión de su estatuto constitucional. El estudio trae causa de la conferencia que impartió el Prof. Morlok en la Facultad de Derecho de la UNED el 9 de abril de 2019 invitado por el Centro de Estudios de Partidos. 


\section{Los partidos como órganos especializados de condicionamiento democrático}

Los partidos políticos se erigen en órganos especializados para el aprovechamiento de las estructuras democráticas institucionalizadas de condicionamiento, sobre todo de las elecciones y de los parlamentos. Una sociedad compleja solo puede alcanzar más altas cotas de desarrollo a través de la especialización. Esto también se predica de las organizaciones. Éstas se constituyen para el cumplimiento de determinadas tareas. Así, existen organizaciones especializadas para la lucha contra los incendios, particularmente los cuerpos de bomberos, para la formación de estudiantes o la investigación, en concreto, en el ámbito de la Universidad. Los partidos tienen como principal cometido la ocupación de los parlamentos a través de las elecciones y la utilización de las posibilidades decisorias parlamentarias para la persecución de sus fines.

Naturalmente el condicionamiento político no solo se ejerce a través de los partidos y la persecución de sus propios fines no solo se desarrolla en el seno del parlamento, como ha puesto en evidencia el surgimiento del lobbysmo. Sin embargo, la característica definitoria de los partidos reside en que su labor se orienta hacia los canales institucionalizados de condicionamiento. Al cumplimiento de esta tarea se encuentran organizadas sus estructuras. La especialización en la adquisición de escaños, en la actividad parlamentaria y en la medida de lo posible, también en la colaboración con los gobiernos, han ido conformando una organización-tipo propia. Por eso los partidos se asemejan entre sí. Los intentos de hacer algo totalmente distinto a los partidos ya existentes derivan regulamente en el fracaso y desembocan finalmente en el desarrollo de los patrones organizativos típicos de los partidos. En consecuencia, los partidos son autosustitutivos. Solo pueden ser sustituidos exitosamente por organizaciones del mismo tipo. Sociológicamente puede hablarse de un isomorfismo de las estructuras de los partidos.

\section{Las funciones de los partidos}

El condicionamiento de los ciudadanos sobre la política tiene como fin primordial materializar sus intereres y convicciones. Empleo el dualismo „intereses y convicciones « para abarcar, tanto sus aspiraciones materiales como ideales. Ambas son principalmente el objeto de las controversias políticas. Los partidos intentan canalizar las aspiraciones de sus votantes en el proceso decisorio del Estado. Son partidos son intermediarios. Son organizaciones sociales que pretenden materializar los intereses y las convicciones en decisiones estatales vinculantes. En particular: a) Los partidos aglutinan intereses sociales, los captan y los recopilan. Unifican intereses próximos entre sí, para alcanzar mayores posibilidades de afirmación. Estos intereses se formulan como fines políticos. b) Las 
instituciones de la política democrática son dirigidas esencialmente por los partidos. Mantienen el sistema político. Propagan sus fines, observan y critican a los partidos concurrentes y contribuyen a la construcción de la opinión pública. Particularmente, intentan orientar las decisiones políticas conforme a sus fines. c) Los partidos intentan materializar sus fines particularmente mediante la ocupación de las posiciones decisorias con su propio personal. Los integrantes de los partidos deben de realizar su programa. Las posiciones más importantes son los escaños parlamentarios y los miembros del gobierno. Las ambiciones políticas personales de los partidos llegan incluso más allá, aspirando a la administración e incluso al poder judicial, lo que jurídicamente resulta cuestionable.

\section{Reconocimiento jurídico como organizaciones especiales}

En su rol como agentes de la transformación de expectativas sociales en decisiones vinculantes los partidos se encuentran jurídicamente protegidos, haciendo especial incapié en su específica función. Todas las democracias europeas, salvo contadas excepciones, gozan de disposiciones constitucionales dedicadas a los partidos, como el art. 6 de la Constitución española o el art. 21 de la alemana. Con frecuencia la posición jurídica de los partidos también se desarrolla en el plano de la ley. En éste se regulan derechos específicos, como los reconocidos durante la campaña electoral, las subvenciones estatales, aunque también determinadas obligaciones, especialmente sobre la transparencia en cuestiones financieras o disposiciones relativas a la garantía de la democracia interna.

\section{LOS GRUPOS PARLAMENTARIOS COMO BRAZO PARLAMENTARIO DE LOS PARTIDOS}

\section{El Parlamento como fin de los partidos}

El parlamento constituye el objetivo de los partidos políticos. En él los partidos intentan materializar sus fines políticos, particularmente, a través de leyes y con la introducción de partidas en el presupuesto. Los diputados proyectan las aspiraciones de los partidos. Los grupos parlamentarios actúan como su brazo intraparlamentario. Esto se expresa con claridad en la denominación inglesa de los grupos parlamentarios: «Party in Parlament».

Naturalmente, han de respetarse los límites jurídicos y dogmáticos entre los partidos y su representación parlamentaria. La función transformadora de los partidos tiene aquí su incidencia. En el camino existente entre la declaración de intereres hasta su plasmación jurídica vinculante existen etapas jurídicamente relevantes. Mientras los partidos son agrupaciones sociales y, por tanto, caen en el ámbito del derecho civil, aunque ciertamente con trascendencia jurídico-pública, los grupos 
parlamentarios se adscriben al ámbito estatal. Existen conforme al derecho parlamentario, no en base al derecho de partidos. Ciertamente, hay que considerar una particularidad: mientras que las funciones y las unidades organizativas del Estado gozan normalmente de una existencia unitaria, los grupos parlamentarios son reflejo de la pluralidad de aquellos partidos políticos que han tenido el necesario éxito electoral. La mayoría de los grupos parlamentarios reflejan, por tanto, una orientación partidista propia, característica de una democracia de partidos.

\section{Los grupos parlamentarios como unidades fundamentales del trabajo parlamentario}

La eficacia del trabajo parlamentario está impulsado por los grupos. Esto se debe a diferentes razones:

a) Vivimos en un mundo complejo. Las soluciones adecuadas para los actuales problemas requieren el empleo de conocimientos específicos. Esta especialización, orientada hacia ámbitos determinados, también es propia de los parlamentarios. Ningún diputado puede ser conocedor, al mismo tiempo, de la política de las pensiones, de la política exterior, del medio ambiente, de la política educativa o del fomento de las regiones. Un parlamento que se ha puesto como objetivo codiseñar y codecidir la política en toda su extensión, impone a sus diputados una demanda de especialización. Éstos solo pueden adquirir una experiencia real, como mucho, en uno o dos ámbitos. La especialización es también una exigencia de la política. En el parlamento procede, por tanto, una división de trabajo. Los diputados fijan su labor en determinadas áreas. Esta división de trabajo se refleja institucionalmente en la creación de comisiones en las que se encuentran diputados especializados en un determinado ámbito.

b) La división de trabajo requiere de organización. Debe de decidirse quién es competente para qué. En términos parlamentarios ello significa determinar qué diputados colaboran en cada comisión. Esta organización del trabajo parlamentario es una tarea de los grupos parlamentarios.

c) Dado que los diputados deben de especializarse, tienen conocimientos limitados en muchos ámbitos de la política. Para poder participar con fundamento en votaciones deben de guiarse por las recomentaciones de aquellos diputados que se han especializado en dichas cuestiones. La división de trabajo presupone, pues, confianza política, de las así denominadas «asociaciones recíprocas de especialistas» (W. Zeh).

He escuchado que en Madrid existe un cierto interés por el fútbol. Podría afirmarse que la labor parlamentaria es un trabajo de equipo. Los grupos 
parlamentarios son equipos que juegan juntos internamente, pero que compiten entre sí.

d) Un ulterior motivo fundamental para la creación de grupos parlamentarios reside en la decisión conforme a la regla democrática de la mayoría. Las mayorías no se logran por sí mismas, sino que deben de organizarse y de mantenerse. Esto tiene lugar en los grupos parlamentarios. Se esfuerzan en que sus miembros en la medida de lo posible voten unitariamente y que sea posible alcanzar una mayoría. También una línea unitaria de votación tiene sentido en los grupos parlamentarios minoritarios: un partido también querría mostrarse hacia afuera como un frente unido en el parlamento. La línea política del partido debe de ser recognoscible y demostrar su eficacia a través de una votación unitaria.

Las mayorías se consiguen a través de compromisos. La decisión mayoritaria fuerza a la construcción de compromisos. Los compromisos con más fáciles cuando las posiciones no se encuentran demasiado alejadas. Esta proximidad es más probable entre diputados con convicciones políticas similares. Es de suponer que éstos se unan para conformar una línea común de votación y potencialmente sean capaces de conformar una mayoría. La mayoría decisoria ejerce una importante presión para que los diputados con similares convicciones políticas se unan en favor de una cooperación continua y también se organicen en torno a una voluntad duradera. Los diputados crean grupos parlamentarios. Bajo los condicionamientos de la orientación partidista de la política surgen grupos parlamentarios del mismo partido. Esto se produce también en interés de los votantes, que constatan cómo sus posiciones se ven representadas eficazmente en el parlamento. Este esfuerzo en favor de una votación unitaria se conoce como «disciplina de partido» o «disciplina de voto».

\section{La prohibición del mandato imperativo}

En cierta contradicción con el decisivo papel de los grupos parlamentarios se encuentra la garantía constitucional de la prohibición del mandato imperativo (art. 67,2 de la Constitución Española y art. 38,1, párrafo 2 de la Ley Fundamental). La defensa de la prohibición del mandato imperativo tiene menos sentido práctico frente a los votantes — dado que conforman una colectividad menos aprehensible - que frente al partido.

La garantía constitucional reconocida a los diputados individualmente considerados se erige en uno de los elementos nucleares del parlamento. A pesar de su importancia real, los grupos parlamentarios constituyen entidades derivadas: los grupos han de comprenderse como agrupaciones libres de parlamentarios. Esta naturaleza derivada de los grupos parlamentarios no solo es una construcción formal. Tras ella se encuentra también una cuestión lógica: los diputados 
necesitan de los grupos para poder desempeñar eficazmente el trabajo parlamentario. Los grupos son intrumentos de los diputados para la efectiva persecución de sus fines políticos.

La decisión parlamentaria de acuerdo con la regla de la mayoría, como se ha visto, requiere de compromisos. Una garantía esencial de la capacidad de decisión reside en la prohibición del mandato imperativo. Un órgano colectivo cuyos miembros se encuentren vinculados a directrices decisorias, no puede unirse en torno a compromisos y existe el peligro de ser incapaz de tomar decisiones. La prohibición de mandato imperativo es un presupuesto esencial para la capacidad del parlamento de adoptar decisiones.

De forma paradójica, ¡la prohibición de mandato imperativo pertenece al elenco de circunstancias que hacen posible y dotan de sentido a la creación de los grupos parlamentarios!

La prohibición de mandato imperativo tiene un ulterior y fundamental sentido. Debe dejar abierto que los diputados puedan llegar a ser influidos por todos los posibles intereses y convicciones. Como representantes de todo el pueblo (art. 38,1, párrafo 2, de la Ley Fundamental), no deben de vincularse a determinados intereses, tampoco a los de su propio partido. Una posible perspectiva demasiado restrictiva que hubiera podido ser inicialmente adoptada, puede así ser ampliada. Ello aumenta la capacidad de respuesta del sistema político.

EXCURSO: todo patrón organizativo tiene ventajas y desventajas. Cada estructura conoce determinadas selectividades. Para compensar estas desventajas es recomendable enriquecer esta estructura mediante una contraestructura, una estructura con una diferente selectividad. La prohibición de mandato imperativo añade una contraestructura a la vinculación a las directrices del grupo parlamentario.

Esta combinación de distintos modelos ha sido probada desde hace tiempo. Puede retrotraerse hasta el concepto de Constitución mixta, que conocemos desde los antiguos. También la división de poderes sigue esta idea de combinación de lógicas distintas.

La prohibición de mandato imperativo contrarresta una excesiva parcialidad de la orientación política en el partido y en el grupo parlamentario. A través de la contradicción entre diputados individuales o uniones de diputados se amplía el horizonte de los grupos parlamentarios. La necesidad de conformar la unidad de voto, en la medida de lo posible de todos los miembros del grupo parlamentario derivada de la regla de la mayoría, hace necesario considerar y crear compromisos con las minorías internas. La participación de un elenco más amplio de aspectos y de intereses revierte en el interés común.

\section{El carácter irrenunciable de los partidos en el parlamento}

Después de todo, los grupos parlamentarios, como organizaciones de trabajo de diputados pertenecientes al mismo partido son irrenunciables en el parlamento. 
Cuanto más intensamente un parlamento asuma la labor de poder codecidir las disposiciones legislativas en sus aspectos más concretos, más importante será el rol de los grupos parlamentarios como base organizativa de la división del trabajo parlamentario.

Independientemente de ello, la función unificadora de los grupos parlamentarios es esencial para la capacidad decisoria de los parlamentos al amparo de la regla de la mayoría. Un parlamento conformado por individualismos corre el peligro de no lograr mayorías y, en consecuencia, de hacerlo incapaz de tomar decisiones. Los comportamientos en el Parlamento de Westminster durante las últimas semanas y meses lo han demostrado. Los parlamentos conducen de manera relativamente rápida a la creación de grupos, como muestra la experiencia histórica, aunque también el desarrollo del parlamento europeo.

La relevancia de los grupos parlamentarios no debe conducir a ignorar que solo el parlamento en su conjunto representa al pueblo, pudiendo hablarse así que una «representación global». Los diputados son representantes de todo el pueblo y como consecuencia de la heterogeneidad del pueblo todos los diputados son también representantes del pueblo. ¿Como un diputado individualmente considerado debería traer a colación los diferentes intereses y convicciones en el Parlamento? Esta pluralidad debe de reflejarse en el parlamento, aunque también, en aras de su capacidad de acción, debe de circunscribirse a las posiciones fundamentales. Este es el rol de los partidos en el parlamento, de los grupos parlamentarios.

Al mismo tiempo, las constituciones democráticas también reconocen la libertad de los diputados. La prohibición de mandato imperativo constituye un contraelemento estructural del poder de los grupos parlamentarios. Incide en la racionalidad general de una democracia parlamentaria. La adopción de decisiones parlamentarias hay que entenderla como un complejo proceso de tratamiento de la información. Éste se lleva a cabo de forma racionalizada en diferentes planos de la toma de decisiones y en un proceso estratificado de la información, a través de diputados especializados, de secciones de trabajo de los grupos parlamentarios, de comisiones, de conversaciones con funcionarios de los ministerios y también con lobbystas.

En vista de este complejo panorama, la confianza en una política orientada al bien común - la confianza es una categoría fundamental de la democracia representativa - se refiere a los acuerdos parlamentarios en la toma de decisiones, soportados esencialmente por los grupos. Desde una perspectiva realista, el fundamento esencial de la confianza en una buena política no es la honestidad de los diputados sino la cooperación ordenada entre aquéllos. Podría hablarse de una „Confianza en el sistema «. En este sistema, los grupos parlamentarios dependen de sus miembros, de sus especialistas.

Se trata, con ello, de una dialéctica de libertad y de compromiso. La inclusión de los diputados en los grupos parlamentarios otorga a aquéllos una verdadera posibilidad de influencia política; la orientación del trabajo parlamentario hacia los grupos hace al parlamento capaz de tomar decisiones y lo predispone hacia un buen trabajo. 
La «inclusión» en un grupo parlamentario es también «compromiso», que supone una merma de la libertad de los diputados. Como cualquier libertad, también la prohibición de mandato imperativo se ve sometida a límites fácticos, también bajo la forma de obligaciones de consideración. La pertenencia a un grupo se basa en un trueque: menoscabo de la libertad por posibilidades de actuación políticamente relevantes.

Una buena labor parlamentaria presupone la existencia de grupos parlamentarios y éstos, por su parte, la presencia de partidos políticos. Esto no se basa solo en el «suministro» de diputados a través de las elecciones, sino también dentro del parlamento.

Title: The function of Political Parties and the Parliament

ABSTRACT: The conditioning of citizens on politics is primarily intended to materialize their interests and convictions; and this is done mainly through political parties. Parties articulate social interests, direct the political institutions and try to materialize their objectives particularly by occupying the decision-making positions. For this reason our democracy owes political parties legal recognition as special organizations, but also the legal it is necessary to analize parliamentary groups as the parliamentary arm of the parties.

RESUMEN: El condicionamiento de los ciudadanos sobre la política tiene como fin primordial materializar sus intereres y convicciones; y ello lo realizan, principalmente, a través de los partidos políticos. Éstos aglutinan intereses sociales, los captan y los recopilan, dirigen las instituciones de la política e intentan materializar sus fines particularmente mediante la ocupación de las posiciones decisorias. Por eso no sólo nuestra democracia debe a los partidos políticos reconocimiento jurídico como organizaciones especiales, debe revalorizarse el análisis jurídico de los grupos parlamentarios como brazo parlamentario de los partidos.

Key words: Political Parties, Parliament, function.

Palabras clave: Partidos políticos, Parlamento, función.

FECHA DE RECEPCIÓN: 05.07.2019

FECHA DE ACEPTACIÓN: 29.07.2019 